\title{
A Distributed Model for Real-Time Flood Forecasting in the Godavari Basin Using Space Inputs
}

\author{
Korada Hari Venkata Durga Rao*, Vala Venkateshwar Rao, Vinay Kumar Dadhwal, \\ Gandarbha Behera, and Jaswant Raj Sharma \\ National Remote Sensing Centre, Indian Space Research Organization (ISRO), Hyderabad 500 625, India
}

\begin{abstract}
Hydrological modelling of large river catchments has become a challenging task for water resources engineers due to its complexity in collecting and handling of both spatial and non-spatial data such as rainfall, gauge-discharge data, and topographic and hydraulic parameters. In this article, a flood forecast model is developed for the Godavari Basin, India through a distributed modelling approach using space inputs. The approach includes rainfall runoff modelling, hydrodynamic flow routing, calibration, and validation of the model with field discharge data. The study basin is divided into 128 subbasins to improve the model accuracy. Topographic and hydraulic parameters of each subbasin and channel are computed using the land use / land cover grid that is derived from the Indian Remote Sensing Satellite (IRS-P6) AWiFS sensor data (56 m resolution), Shuttled Radar Topographic Mission (SRTM) Digital Elevation Model (DEM), and the soil textural grid. The model is calibrated using the field hydrometeorological data of 2000 and validated with the data of 2001. The model was tested during the 2010 floods with real-time 3-hour interval hydrometeorological and daily evapotranspiration data. Accuracy in estimating the peak flood discharge and lag time was found to be very good. Flood forecast lead time is increased by 12 hours compared to conventional methods of forecasting.
\end{abstract}

Keywords digital elevation model, distributed hydrological modelling, flood routing, Godavari Basin, real-time flood forecasting

\section{Introduction}

Floods are natural disaster events that, by their nature, may expose any nation's population to the risk of death or injury and may damage or destroy private and public properties, infrastructure, and agricultural or other developed land (Gupta et al. 2001). Flooding constitutes the most prevalent and costly natural disaster in the world. In recent years, satellite technology has become extremely important in providing cost-effective, reliable, and crucial mechanisms for preparedness, damage control, and relief management of flood

\footnotetext{
* Corresponding author. E-mail: khvdurgarao@yahoo.com
}

disasters. A variety of mitigation measures can be identified and implemented to reduce or minimize the impact of flooding. Such mitigation measures include flood forecasting and warning, adopting proper land-use planning, flood-prone area zoning, and management. Improving regional flood risk forecasting requires extensive flood-related information. Traditionally, gathering and analyzing hydrologic data related to floodplains and flood-prone areas have been a timeconsuming effort requiring extensive field observations and calculations. With the development of remote sensing and computer analysis techniques, traditional techniques now can be supplemented with these new methods of acquiring quantitative and qualitative flood hazard information.

Complete control of floods is neither physically nor economically possible. Forecasting of floods enables warnings to be given to the people likely to be affected by them and civil defence measures to be organized in a timely manner. Forecasting thus constitutes a very effective, important, and relatively inexpensive nonstructural flood control measure (Subramanya 1991). Simple correlations between upstream and downstream gauge station flows can be used for shortrange forecasts. Application of rainfall runoff models and unit hydrograph techniques can be used for medium-range forecasts of small catchments.

Jaun and Ahrens (2009) studied the limitation of probabilistic forecasting system, which is based on a hydrometeorological ensemble prediction approach. Thielen et al. (2009) presented the development of the European Flood Alert System (EFAS), which aims at increasing preparedness for floods in transnational European river basins by providing local water authorities with medium-range, probabilistic flood forecasting information 3 to 10 days in advance. Durga Rao, Bhanumurthy, and Roy (2009) have worked on developing a medium-range flood forecast model for the Brahmaputra Basin. They demonstrated the scope of using satellite-based rainfall products in flood forecasting and its limitations. Bogner and Kalas (2008) tested for adjusting the ensemble traces using a transformation derived from simulated and observed flows in the Upper Danube. Their work involved the combination of state-space models and wavelet transformations in order to update errors between the simulated (forecasted) and the observed discharges. 
Sahoo and Ray (2006) discussed the application of feedforward back propagation and radial basis function neural networks for flow prediction of a Hawaii stream and one of its tributaries that exhibits flash flood behavior. The performance of artificial neural networks was examined for two input data sets: one set with and the other set without mean velocity, but including stream stage, width, and crosssectional area for two gauging stations on the stream. The results show that for both input data sets, well-optimized neural networks can outperform rating curves for discharge forecasting. Jain, Kothyari, and Ranga Raju (2004) demonstrated the application of a Geographic Information System (GIS) in distributed rainfall runoff modeling. They derived model inputs such as slope, flow direction, and overland flow sequencing (drainage path) for each cell of the catchment using a digital elevation model and information about land use, soil, and so forth derived through digital analysis of satellite data and published information. Overland flow was described by the diffusion wave approximation of St Venant equations. Results from several catchments indicate that the model can simulate reasonably well the runoff hydrograph at the catchment outlet. The model also realistically predicts temporal variation of the spatial distribution of flow depth and runoff over the catchment. Tsai (2004) investigated theoretically on unsteady flow routing in a mild-sloped river with gradually varying flow depth induced by the downstream backwater effect. Linear stability analysis was adopted to study the physical mechanisms responsible for wave attenuation or amplification, and wave retardation or acceleration in open channels when the flow is spatially varying. The downstream backwater effect on wave characteristics of various widely used flood routing models was discussed.

De Roo et al. (2003) developed a prototype flood forecast system for European test basins. They used real-time rainfall and rainfall forecast grids of coarse resolution for flood forecasting at basin scale by integrating hydrological models with weather forecasts. A flood-forecasting system has been developed by the Danish Hydraulic Institute in collaboration with the Bangladesh Water Development Board for the part of the Brahmaputra River that falls in Bangladesh territory. Telemeteorological rainfall data were used in this study. Runoff was computed for the catchment area within Bangladesh and added to the inflow discharges measured at upstream sections of the river within the Bangladesh area (Jorgensen and Host-Madsen 1997).

The Central Water Commission (CWC) of India is the pioneer organization for flood forecasting in India. Short-range forecasting is being done by $\mathrm{CWC}$ in the Godavari Basin using gauge-to-gauge correlation technique (CWC 1989). Development of medium-range flood forecast models in river basins using hydrological models is essential to mitigate flood damage. Considering the current state of research in the field and the need for forecasting, the present research focuses on the development of a medium-range flood forecast model for the Godavari Basin in HEC-HMS and HEC-Geo HMS modelling environment (U.S. Army Corps of Engineers 2000, 2001, 2003). The model is validated with 3-hour real-time hydrometeorological data from 2010.

\section{Geographical Setting of the Godavari Basin}

Godavari Basin extends over an area of $312,812 \mathrm{~km}^{2}$, covering nearly 9.5 percent of the total land area of India. The Godavari River is perennial and is the second largest river in India. The river joins the Bay of Bengal after flowing a distance of $1470 \mathrm{~km}$ (CWC 1999). It flows through the Eastern Ghats and emerges into the plains after passing Koida. Pranahita, Sabari, and Indravati are the main tributaries of the Godavari River (Figure 1). The basin receives the major part of its rainfall during the Southwest Monsoon period. More than 85 percent of the rain falls from July to September. Annual rainfall of the basin varies from 880 to $1395 \mathrm{~mm}$ and the average annual rainfall is $1110 \mathrm{~mm}$. Floods are a regular phenomenon in the basin. Badrachalam, Kunavaram, and the deltaic portion of the river are prone to floods frequently. Perur and Koida gauge stations are the main base stations of the Central Water Commission for flood forecasting in the basin. Geographic setting and locations of these base stations are shown in Figure 1.

\section{The Modelling Approach and Methodology}

In a distributed modelling the spatial variations of topographic and meteorological parameters are considered and the runoff is computed in the spatial domain. In this approach, there are sources, sinks, and boundary conditions besides the other geospatial data; a GIS platform with the integration of satellite data offers an excellent solution. HEC-HMS and HEC-Geo HMS are used as a modelling environment for developing the flood forecast model for the Godavari Basin. The base model setup consists of two main modules, the topographic model and the meteorological model.

\subsection{Topographic Model Setup}

The physical representation of watersheds or basins and rivers is configured in the topographic model. Hydrological elements are connected in a dendritic network to simulate runoff processes. Available elements in the topographic model are: subbasin, reach, junction, reservoir, diversion, source, and sink. Computation in the model proceeds from upstream elements in a downstream direction. Various thematic layers such as land use, soil texture, subbasins, and so on that are required for the topographic model are prepared in an ArcGIS environment. 


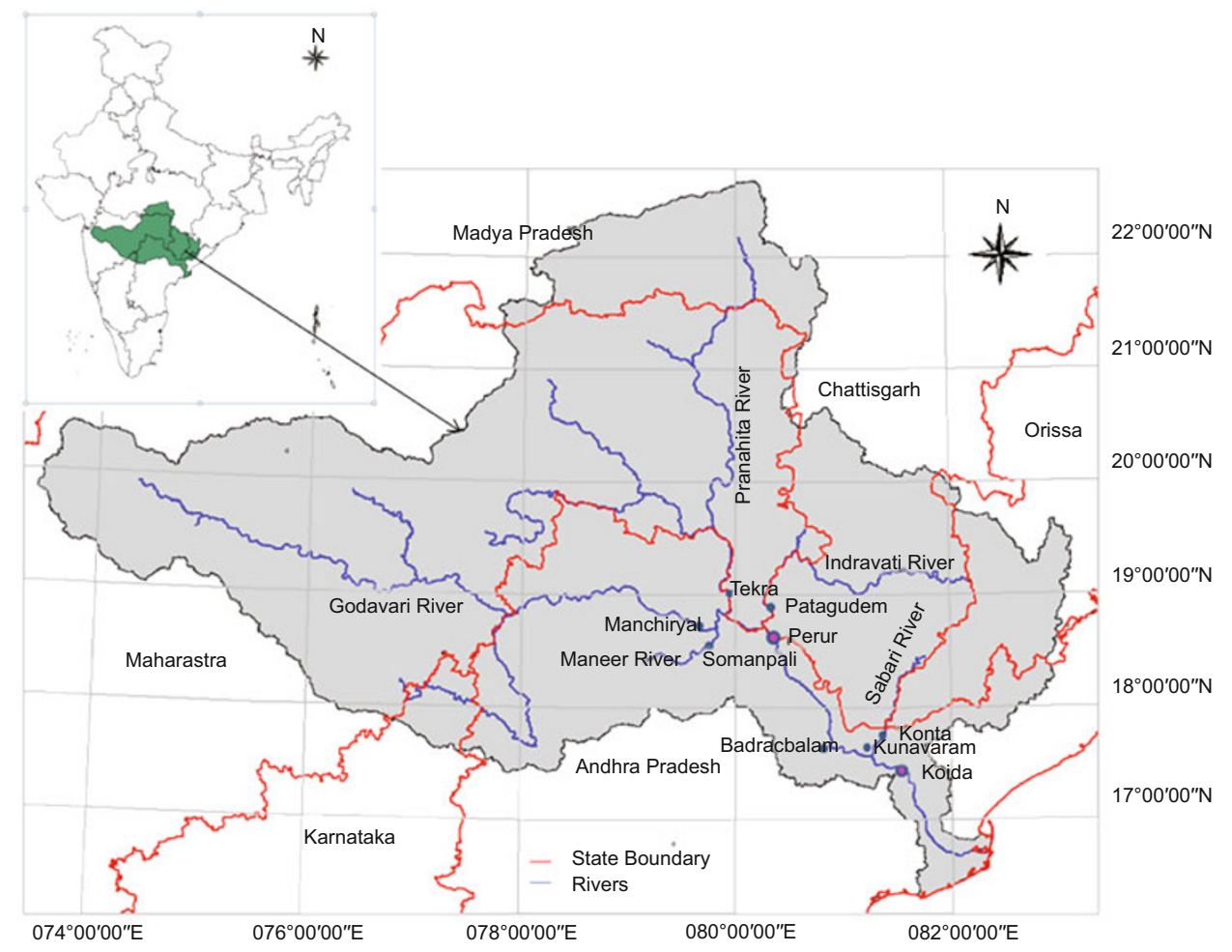

Figure 1. Geographic setting of the Godavari Basin

\subsubsection{Spatial and Non-Spatial Databases}

The study area is covered by three scenes of the Indian Remote Sensing (IRS)-P6 Advanced Wide Field Sensor (AWiFS) satellite images of $56 \mathrm{~m}$ resolution. Satellite data of 2004 were georeferenced using topographic maps and used for basin and subbasin boundary finalization and land-use grid preparation.

Land use / land cover is a very important parameter in hydrological modelling. Evapotranspiration, interception, and catchment characteristics are mainly dependent on this input. Considering its hydrological characteristics, land use is further reclassified into a hydrological land use / land cover map as shown in Figure 2. Land-use type with hydrologically poor condition indicates more runoff potential and vice versa. Parameters derived from the land-use map are used in runoff estimation and in hydrodynamic flow routing.

In the hydrological cycle, infiltration is a major component. Infiltration depends on soil texture, which in conjunction with land use provides various basin parameters for the modelling. A soil textural map of the study area at the 1:250,000 scale was obtained from the National Bureau of Soil Sciences and Land-Use Planning of India and converted into digital format. Soil textural classes present in the study area are shown in Figure 3.

The Digital Elevation Model (DEM) is the main input for topographic parameter extraction. Runoff flow within a watershed and in a channel depends on the slope of the watershed and channel respectively. The Shuttle Radar
Topographic Mission (SRTM) DEM of $90 \mathrm{~m}$ resolution is used to extract various topographic and hydraulic parameters of the basin such as subbasin and channel slopes, Manning's coefficients, lag time, time of concentration, and so on. Subbasins and drainage network are also delineated using the DEM through an automated process.

\subsubsection{Terrain Processing}

Terrain pre-processing is a series of steps to derive various topographic and hydraulic parameters. These steps consist of computing the flow direction, flow accumulation, stream definition, watershed delineation, watershed polygon processing, stream processing, and watershed aggregation. Computations can be done step by step or in batch manner. Once these data sets are developed, they are used in later steps for subbasin and stream delineation. The basin model file contains the hydrologic data structure, which includes the hydrologic elements, their connectivity, and related parameters. All topographic and hydraulic parameters are computed in the terrain processing stage using land use and soil texture information and DEM, and exported to the topographic model.

Main streams were digitized using the satellite data and were fused on the SRTM DEM using the burn streams technique. This technique facilitates delineating subbasins and streams in flat topography more accurately. The burned DEM was used in calculating flow direction and flow accumulation. Upstream drainage area at a given cell can be calculated 


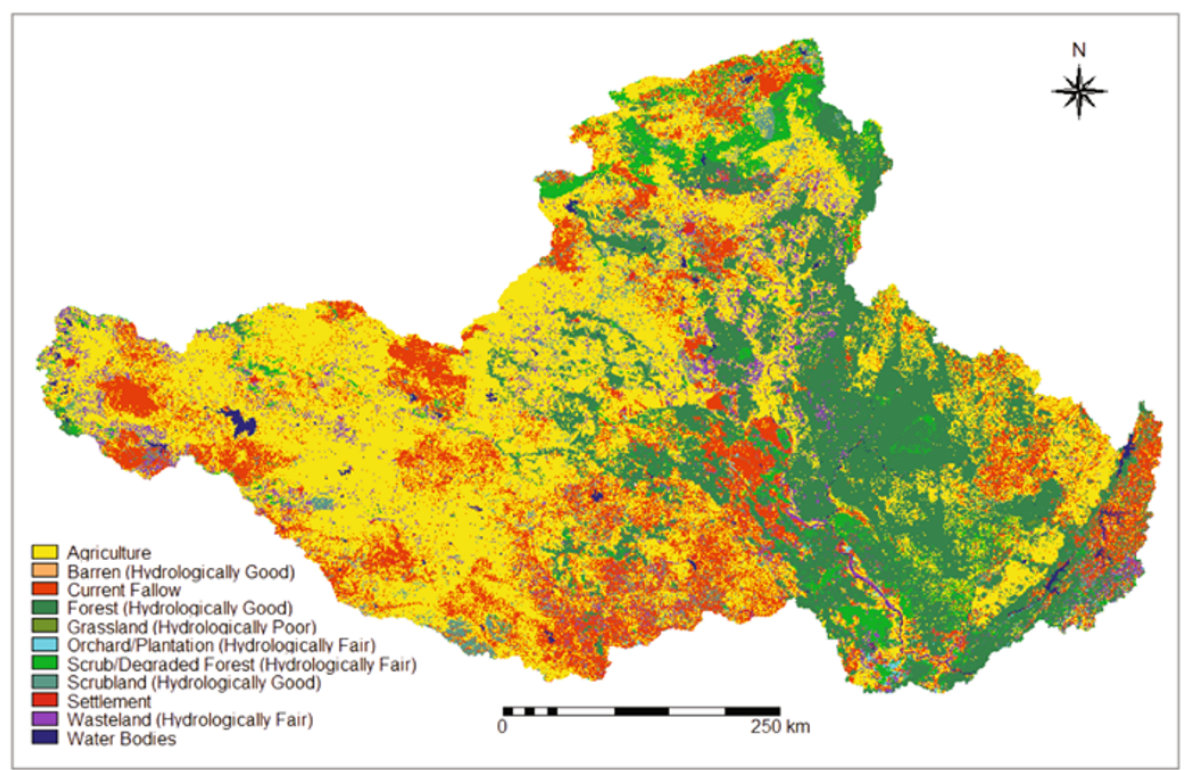

Figure 2. Hydrological land cover of the Godavari Basin

by multiplying the flow accumulation value by the cell area. Stream definition classifies all cells with flow accumulation greater than the user-defined threshold as cells belonging to the stream network. Streams in the basin have been delineated using this automated technique. Stream segmentation divides the stream into segments. Stream segments are links that connect two successive junctions, a junction and an outlet, or a junction and the drainage divide. The subbasin delineation process delineates a basin or watershed for every stream segment. Keeping in mind the spatial extent of the basin, computational time, and the desired accuracy, the basin is divided into 128 subbasins.

\subsubsection{Hydrologic Parameter Extraction}

Topographic characteristics of streams and watersheds have been computed using a model pre-processor. These characteristics are useful in estimating hydrological parameters of basins and for comparing the basins. Physical characteristics of all streams and basins are stored in the attribute tables that can be exported to the model for further modelling processes. The physical characteristics that are extracted for the streams and subbasins are river length, river slope, basin centroid, longest flow path, centroidal flow path, and so forth. When the stream and subbasin physical characteristics are extracted,

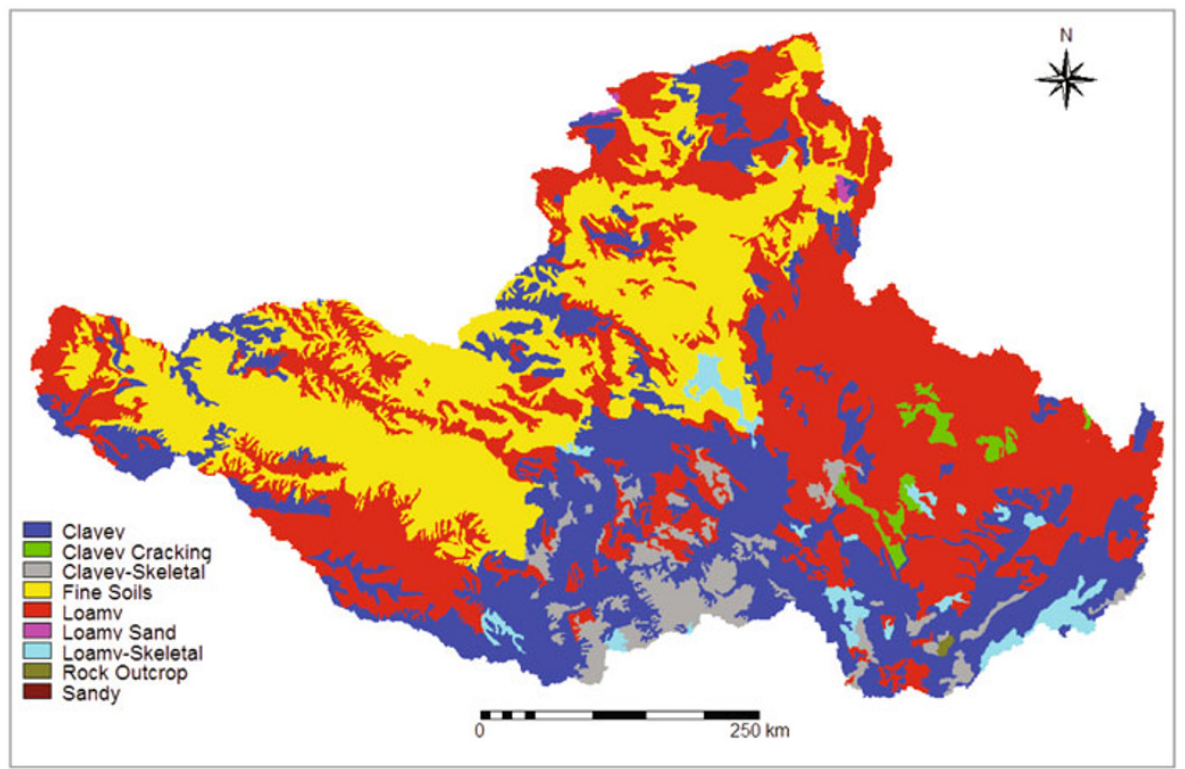

Figure 3. Soil textural classes in the Godavari Basin 
hydrological parameters can be easily derived. Infiltration rate is estimated as grid-based quantities that are based on land use and soil types. Other hydrological parameters such as time of concentration, lag time, and Muskingum routing parameters are computed from the terrain characteristics. All the above-mentioned hydrological parameters are extracted for all the subbasins of the study area in a GIS environment and fed into the model. Complete topographic model setup is shown in Figure 4.

\subsection{Hydrometeorological Model Setup}

The response of a watershed is driven by precipitation that falls on the watershed and evapotranspiration from the watershed. The precipitation may be the observed rainfall from a historical event or it may be a frequency-based hypothetical rainfall event. Historical data may be useful for calibration and validation of model parameters. Rainfall data from nearly 272 stations covering the entire area uniformly were obtained for the years 2000 and 2001 from various organizations including the India Meteorological Department (IMD) and Andhra Pradesh Disaster Management Centre, India. These data were used in the calibration and validation of the complete model. Rainfall grids of the basin of these two years were prepared by interpolating the point observations using the Inverse Distance Weight (IDW) method in ArcGIS. Out of the data from 272 stations, those from nearly 220 stations were used in interpolation and the rest were used for validation of the interpolated grids covering the study area. Other interpolation techniques including the spheroid method and linear interpolation were also examined. From the validation, it was found that the IDW method suits the study area best.
Figure 5 illustrates the rainfall grid of 19 July 2001. Daily rainfall of all the subbasins was extracted from these grids and fed into the model. River gauge level and discharge data of various stations in the basin were collected from the Central Water Commission and used for model calibration and validation. Discharge data of 2000 were used for model calibration and the 2001 data were used for validation of the model as there were high floods during these two years. Gauge-discharge data (elevation-discharge) of the two main flood forecast stations Perur and Koida were used for computing flood level along with the discharges. For real-time validation, 3-hour real-time hydrometeorological data of 2010 of various hydrometeorological stations were used.

\subsection{Model Setup and Simulation Runs}

In this study, the distributed modelling approach is adopted in flood hydrograph computation. The methodology involved in computing the flood hydrograph of the basin at the outlet can be broadly divided into five stages, including computing runoff volume (excess rainfall), modelling direct runoff, flood routing, calibration of the model, and model validation. Various best possible modelling algorithms were used in each stage of computation based on the data available and subbasin characteristics.

The surface runoff (excess rainfall) in each pixel will drain towards the outlet of the subbasin/basin. The process is referred to as the "transformation" of precipitation excess into point runoff, that is, the computation of the flood hydrograph at each subwatershed outlet, and it is measured with reference to time. Kinematic Wave Model and SCS-Unit Hydrograph techniques are used for direct runoff estimation.

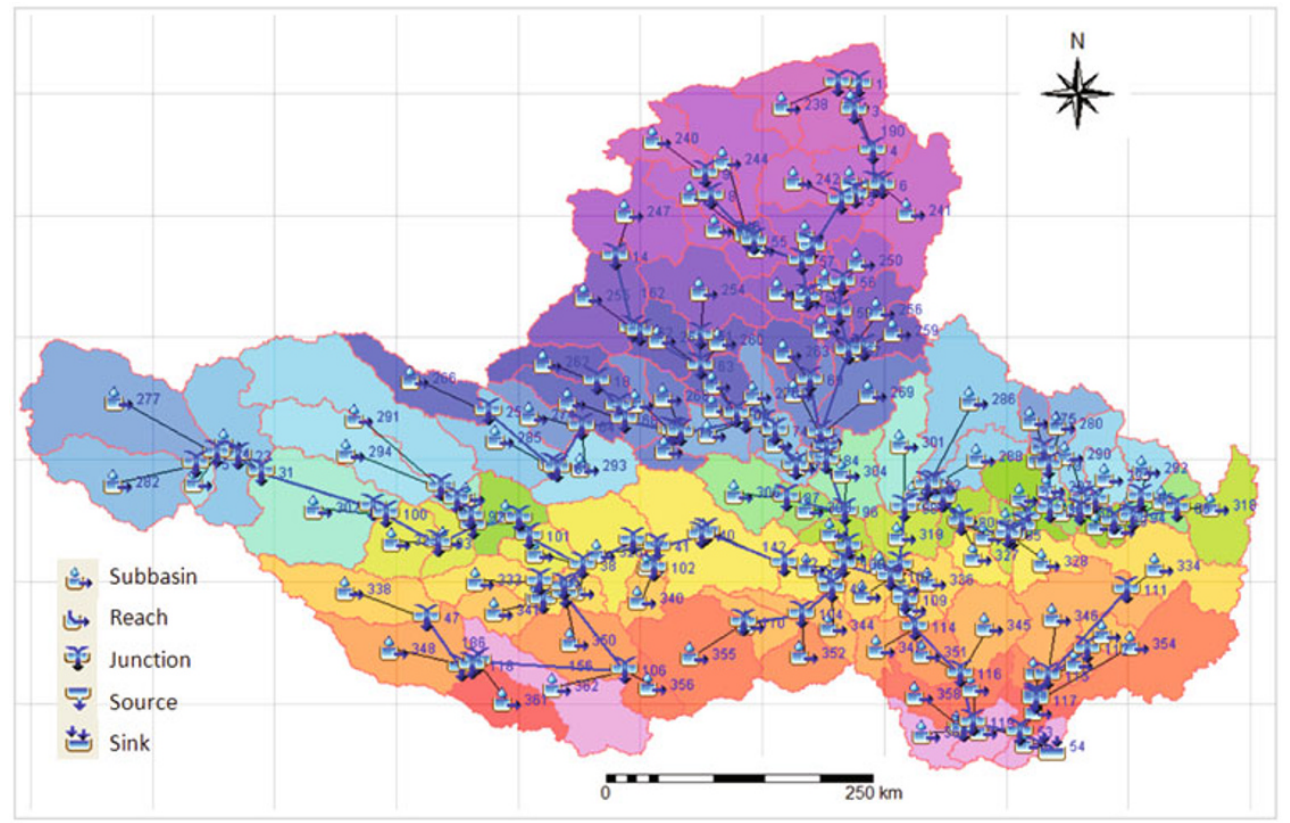

Figure 4. Topographic model of the Godavari Basin 


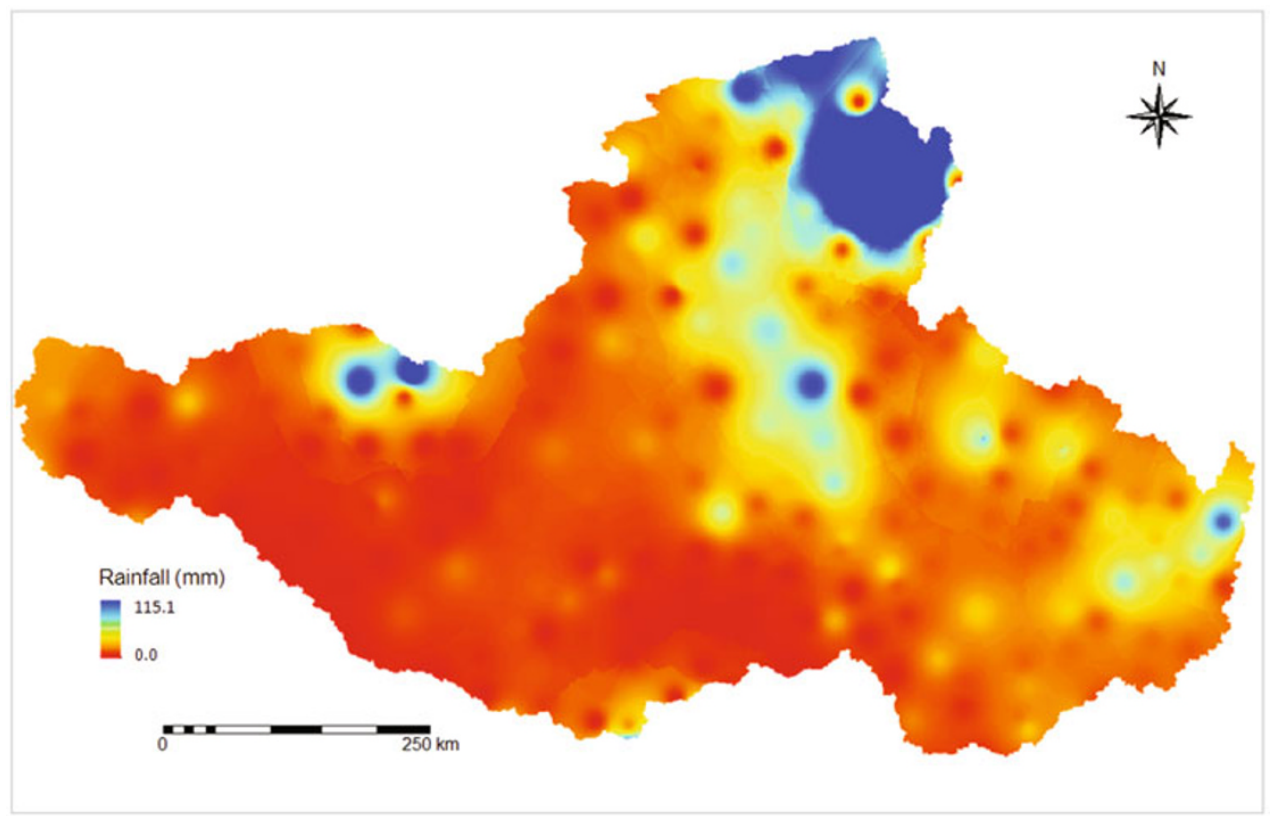

Figure 5. Rainfall grid of the Godavari Basin for 19 July 2001

These models are selected based on the subbasin size, shape, and slope. A brief description of these models is given below.

Kinematic Wave Model: This model represents the watershed as an open channel. Using this model runoff can be modelled separately for pervious and impervious terrains (U.S. Army Corps of Engineers 2000).

The one-dimensional flow momentum equation can be expressed as:

$$
\begin{gathered}
S_{f}=S_{o}-\frac{\partial y}{\partial x}-\frac{V}{g} \frac{\partial V}{\partial x}-\frac{1}{g} \frac{\partial V}{\partial t} \\
A \frac{\partial V}{\partial x}+V B \frac{\partial y}{\partial x}+B \frac{\partial y}{\partial t}=q \\
\text { (Continuity Equation) }
\end{gathered}
$$

Eq. 1

For shallow flow conditions equation 2 can be expressed as:

$$
\frac{\partial A}{\partial t}+\frac{\partial Q}{\partial x}=q
$$

$$
\begin{array}{ll}
\frac{\partial y}{\partial x}=\text { Pressure Gradient } & V B \frac{\partial y}{\partial x}=\text { Wedge Storage } \\
\frac{V}{g} \frac{\partial V}{\partial x}=\text { Convective Acceleration } & A \frac{\partial V}{\partial x}=\text { Prism Storage } \\
\frac{1}{g} \frac{\partial V}{\partial t}=\text { Local Acceleration } & B \frac{\partial y}{\partial t}=\text { Rate of Rise } \\
S_{f}=S_{o} & S_{f}=\text { Energy Gradient } \\
& S_{o}=\text { Bottom Slope }
\end{array}
$$

$$
Q=\frac{R^{2 / 3} S_{f}^{1 / 2}}{N} A \text { (Manning's Equation) } \quad \text { Eq. } 4
$$

$$
\begin{gathered}
Q=\alpha A^{m} \\
\alpha=\frac{1.486 S^{1 / 2}}{N}, m=5 / 3
\end{gathered}
$$

Eq. 5

Combining equations 3 and 5

$$
\frac{\partial A}{\partial t}+\alpha m A^{(m-1)} \frac{\partial A}{\partial x}=q
$$

where, $B=$ water surface width, $V=$ velocity of flow, $q=$ rainfall excess per unit width of the channel, and $N=$ overland roughness factor.

SCS (Modified) Unit Hydrograph Technique: The Soil Conservation Service (SCS) proposed a parametric unit hydrograph (UH) model (SCS 1972). The model is based on averages of UH derived from gauged rainfall and runoff for a large number of watersheds. The model considers the dimensionless SCS hydrograph, topographic, and meteorological parameters in computing the unit hydrograph. The description of the model is as follows:

$$
\begin{aligned}
Q_{\text {peak }} & =\frac{2.8 R^{*} A}{T_{\text {peak }}} \\
T_{\text {peak }} & =\frac{D}{2}+T_{\text {lag }} \\
T_{\text {lag }} & =\frac{L^{0.8}\left(\frac{1000}{C N}-9\right)^{0.7}}{734.45 \sqrt{S}}
\end{aligned}
$$

$L=890 A^{0.65}$

$T_{c}=0.6 T_{\mathrm{lag}}$ 
where, $Q_{\text {peak }}$ is peak discharge, $T_{\text {peak }}$ is time to peak, $T_{\text {lag }}$ is time lag, $S$ is slope of the watershed, $C N$ is curve number, $A$ is area of the watershed, and $L$ is hydraulic length of the watershed.

In this study, the straight line method, a popular method used for the computation of base flow in each subwatershed, is adopted. Monthly evapotranspirations are computed using the Priestley-Taylor method and fed into the model.

Flood Routing: Once direct runoff in each watershed is calculated, it has to be routed to the main outlet. A flood wave is attenuated by friction and channel storage as it passes through a reach. The process of computing the travel time and attenuation of water flowing in the reach is often called routing. Travel time and attenuation characteristics vary widely between different streams. The travel time is dependent on characteristics such as length, slope, friction, and flow depth. Attenuation is also dependent on friction, in addition to other characteristics such as channel storage. Direct runoff of various subbasins has been routed to the main outlet at Koida using Muskingum-Cunge and modified SCS lag methods. The Muskingum-Cunge method was used where multiple channel slopes were found.

After completing the model setup, trial runs were executed to obtain results. Each run combines a topographic model, meteorological model, and control specification components with run options. All errors such as missing sink and source nodes, channel connectivity, and so on in model setup were rectified during trial runs. Runs can be re-executed at any time to update results when data in the components are changed.

\subsection{Model Calibration and Validation}

Model calibration is the process of adjusting model parameter values until model results match historical data. The process can be completed using engineering judgement by repeatedly adjusting parameters and computing and inspecting the goodness-of-fit between the computed and observed hydrographs. Significant efficiency can be realized with an automated procedure (U.S. Army Corps of Engineers 2001). The quantitative measure of the goodness-of-fit is the objective function. An objective function measures the degree of variation between computed and observed hydrographs. The key to automated calibration is a search method for adjusting parameters to minimize the objective function value and to find optimal parameter values.

A hydrograph is computed at the target element (outlet) by computing all of the upstream elements and by minimizing the error (minimum deviation with the observed hydrograph) using the optimization module. Parameter values are adjusted by the search method; the hydrograph and objective function for the target element are recomputed. The process is repeated until the value of the objective function reaches the minimum to the best possible extent. During the simulation run, the model computes direct runoff of each watershed and the inflow and outflow hydrograph of each channel segment. The model computes the flood hydrograph at the outlet after routing flows from all subbasins to the basin outlet. The computed hydrograph at the outlet is compared with the observed hydrograph at Perur and Koida stations.

After computing the exact value of the unknown variable during the calibration process, the calibrated model parameters are tested for another set of field observations to estimate the model accuracy. In this process, if the calibrated parameters do not fit the data of validation, the required parameters have to be calibrated again. Thorough investigation is needed to identify the parameters to be calibrated again. In this study, hydrometeorological data of 2001 were used for model validation because floods occurred in that year.

\section{Real-Time Validation of the Model}

The developed model has been validated thoroughly at the Central Water Commission Office in Hyderabad with the 3-hour interval, real-time hydrometeorological data during the floods of 2010 (the simulation period is 15 June to 15 October 2010). Considering the availability of real-time data, discharge data of the Pranahita (at Tekra), Godavari (at Manchiryal), Indravati (at Patagudem), Maneer (at Somanpalli), and Sabari (at Konta) rivers (Figure 1) were fed into the model as inputs. Rainfall runoff modelling was done in all the subbasins located in the study area down to the above mentioned stations. Hydrodynamic flow routing was also done in all the river channels. In real-time validation, the total flood routing stretch is approximately $330 \mathrm{~km}$ long (Manchiryal to Koida). The selected river reach in this study covers the maximum flood-prone area in the Godavari River basin.

\section{Results and Discussion}

Agricultural land is the predominant land-use type in the study area that is severely exposed to floods every year. Slopes in the deltaic portion of the river are very flat (less than 3 percent), causing frequent inundation in this area. Soils in the study area are very fine in texture, resulting in more runoff. In this research, the IDW method was found to be a suitable technique of rainfall interpolation for the basin, by which the rainfall grids calculated are more accurate than the Thiessen polygon or isohyetal methods. Gauge-discharge data of Perur and Koida stations were used in calibrating and validating the model as these two stations are the main flood forecast stations in the basin. The computed hydrograph during the validation process and observed hydrograph at Perur and Koida stations are shown in Figures 6 and 7 respectively. These figures indicate that the computed hydrographs match well with the observed hydrographs.

Real-time flood forecasting was given by continuous simulation of flood hydrographs using the real-time hydrometeorological data of the 2010 flood season. Subsequently, simulated discharges were compared with the field observed 


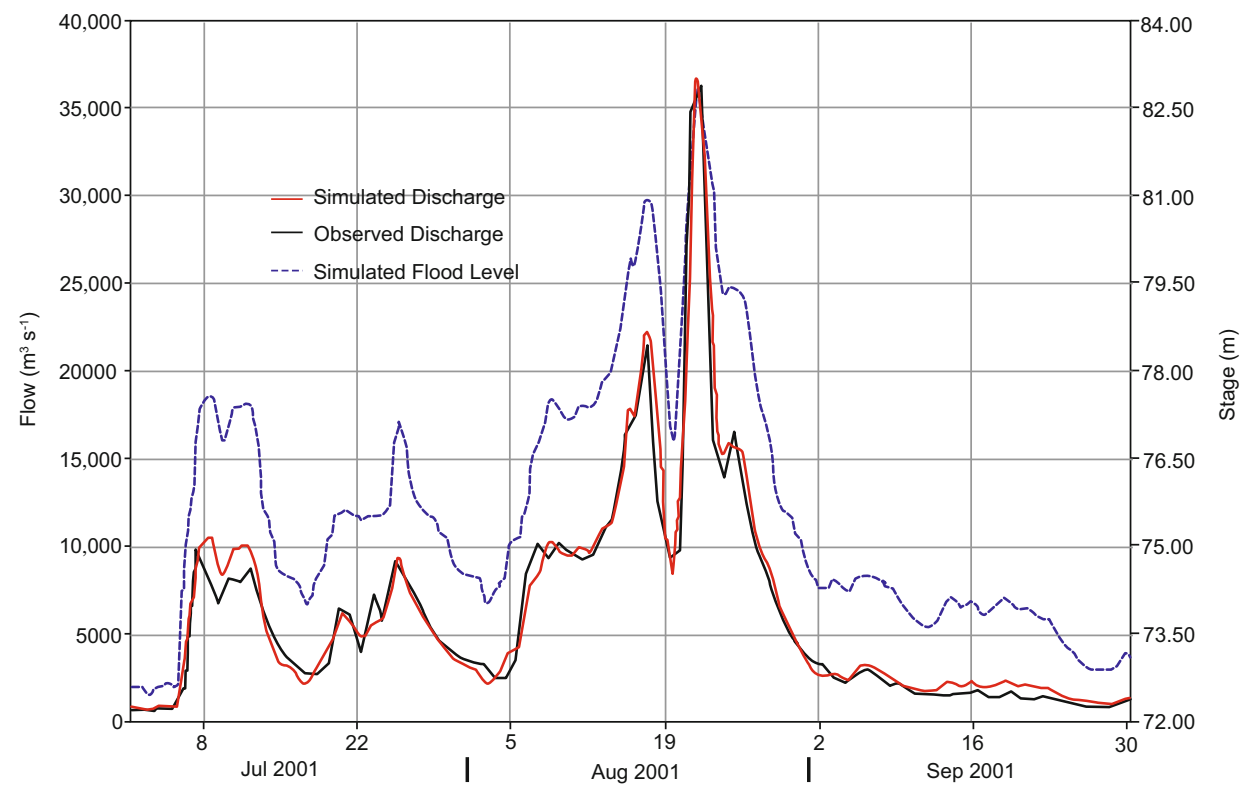

Figure 6. Observed and computed flood hydrographs at Perur, Godavari Basin, India (2001)

discharges at Perur and Koida. Computed and observed flood hydrograph at Koida, the final outlet of the study area, is shown in Figure 8. The computed flood discharges match very well with the real-time observed flows. The Godavari River experienced severe flood events on 9 August 2010 and 11 September 2010. The model could forecast both flood peaks exactly. Accuracy in computing peak discharge during the flood events was 87 percent when compared to the observed flows. Model computations are 13 percent higher than the observed discharges. This error may be due to floodplain inundation between the Perur and Koida stations that the model could not take into account. The model is more than 90 percent accurate in computing discharges when there is no floodplain inundation. The difference between the observed flood event time and simulated flood event time was less than two hours.

Flood forecast lead time is increased by 12 hours compared to the present conventional method. Due to the hydrological modelling technique, accuracy in discharge computations is improved. As the gauge-discharge function (relation) data is fed into the model for Perur and Koida stations, the model can forecast the flood levels along with the

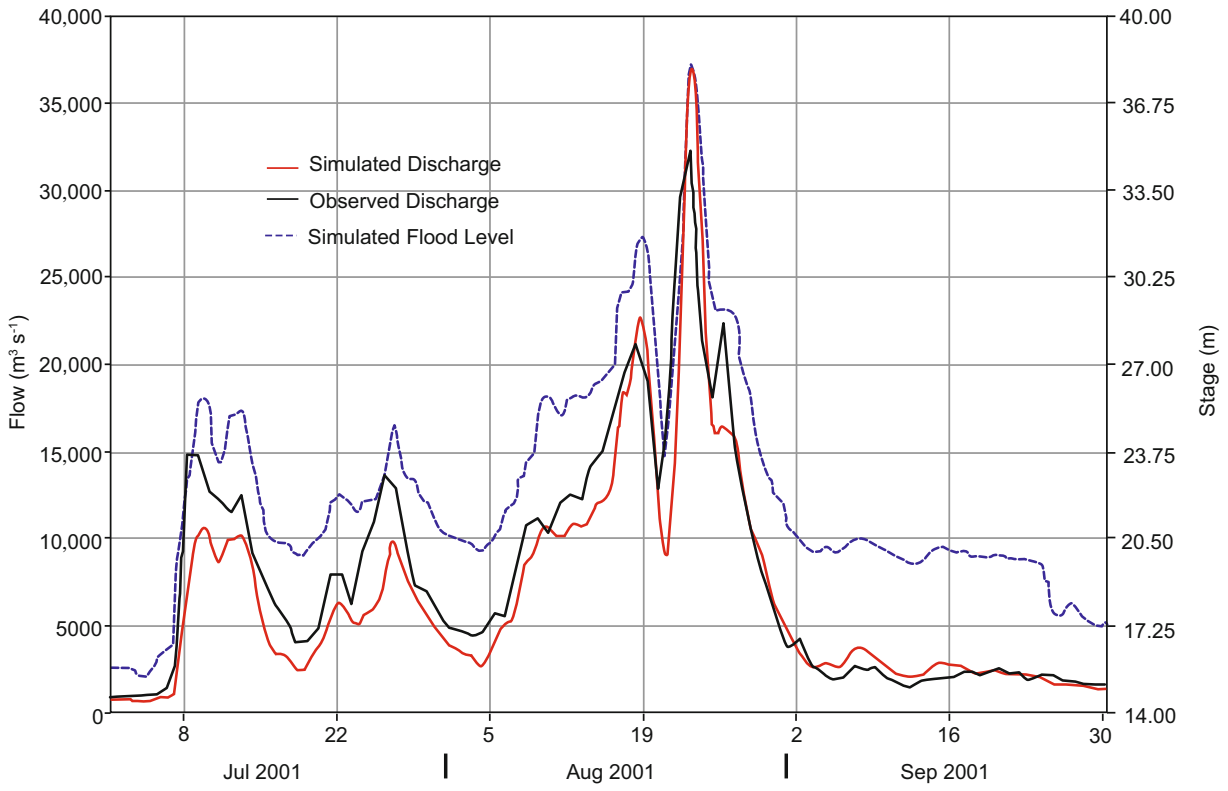

Figure 7. Observed and computed flood hydrographs at Koida, Godavari Basin, India (2001) 


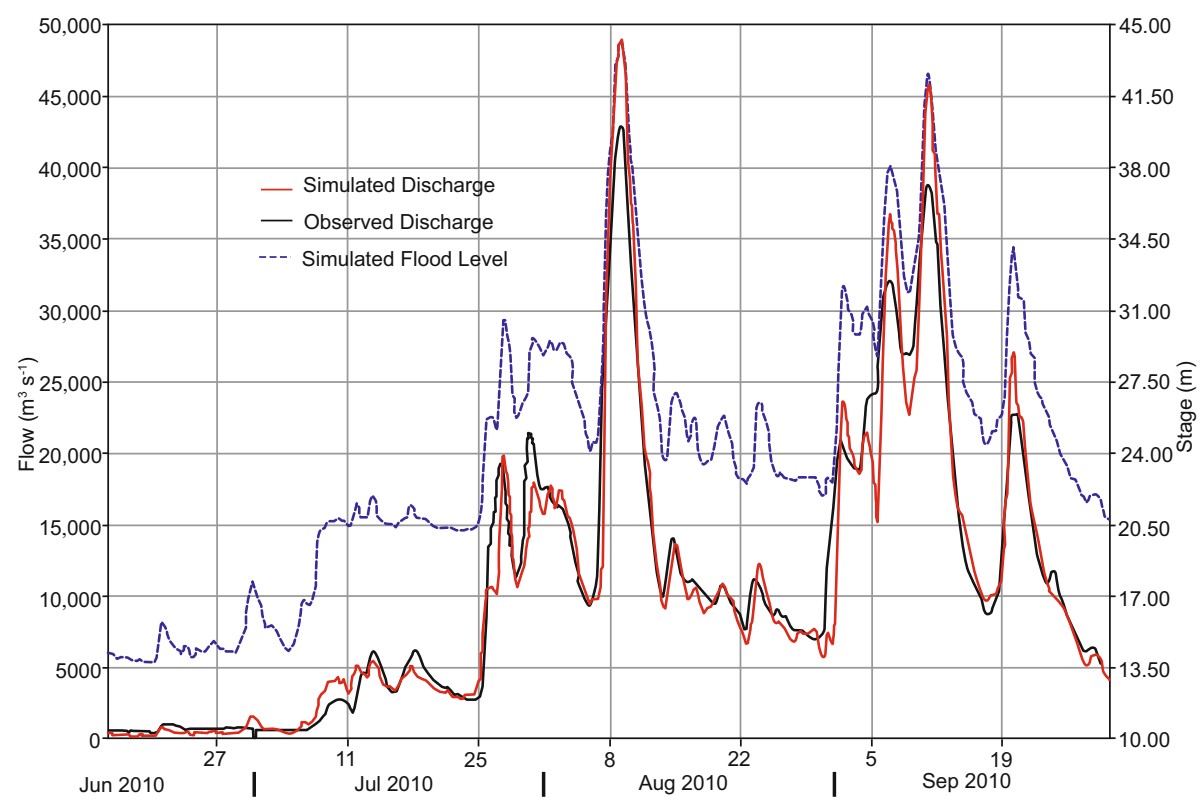

Figure 8. Real-time computed and observed flood hydrographs at Koida, Godavari Basin, India (15 October 2010)

discharges at these stations. Flood discharge at any river confluence can also be computed. This will help in forecasting flood discharges at intermediate river junctions. Discharge in any subbasin of the study area can be predicated separately with the adoption of this hydrological modelling approach.

\section{Conclusion}

The simulations show that the computed hydrographs match well with the observed hydrographs. These hydrographs match very well when the discharge in the river is less than $30,000 \mathrm{~m}^{3} \mathrm{~s}^{-1}$. Error will increase slightly when discharge is beyond this range, due to floodplain inundation. Floodplain inundation causes slightly higher model computations as compared to the observed values. With this hydrological modelling approach, accuracy in discharge computations is improved compared to conventional methods, flood forecast at any river confluence can be issued, and influence of any tributary can be examined separately. In the real-time application the flood forecast model improved the lead time by 12 hours compared to conventional methods of forecasting. The calibrated model is found quite stable in real-time operations. Model accuracy can be further improved by computing floodplain inundations.

\section{Acknowledgments}

The authors sincerely thank Dr. R. R. Navalgund, Chairman, EOAM-MC for assigning the responsibility and providing constant support and guidance to the authors. The first author sincerely acknowledges the support and guidance provided by Dr. P. S. Roy, former Dy. Director, RS GIS AA, NRSC, as well as the support provided by Sri. V. N. Wakpanjar and Sri. M. Raghuram, CWC, Hyderabad for providing the field data and supporting the real-time validation of the model at the Central Water Commission, Hyderabad.

\section{References}

Bogner, K., and M. Kalas. 2008. Error Correction Methods and Evaluation of an Ensemble Based Hydrological Forecasting System for the Upper Danube Catchment. Atmospheric Science Letters 9 (2): 95-102.

CWC (Central Water Commission of India). 1989. Manual on Flood Forecasting. New Delhi: Central Water Commission.

. 1999. Reassessment of Water Resources Potential of India. New Delhi: Central Water Commission.

De Roo, A., B. Gouweleeuw, J. Thielen, P. Bates, M. Horritt, et al. 2003. Development of European Flood Forecasting System. International Journal of River Basin Management 1 (1): 49-59.

Durga Rao, K. H. V., V. Bhanumurthy, and P. S. Roy. 2009. Application of Satellite Based Rainfall Products and SRTM DEM in Hydrological Modelling of the Brahmaputra Basin. Journal of Indian Society of Remote Sensing 37 (4): 539-52.

Gupta, M. C., V. K. Sharma, L. C. Gupta, and B. K. Tamini, eds. 2001. Manual of Natural Disaster Management in India. National Centre for Disaster Management, Ministry of Agriculture, Government of India.

Jain, M. K., U. C. Kothyari, and K. G. Ranga Raju. 2004. A GIS Based Distributed Rainfall-Runoff Model. Journal of Hydrology 299 (1-2): $107-35$

Jaun, S., and B. Ahrens. 2009. Evaluation of a Probabilistic Hydrometeorological Forecast System. Hydrology and Earth System Sciences 13: $1031-43$.

Jorgensen, G. H., and J. Host-Madsen. 1997. Development of a Flood Forecasting System in Bangladesh. In Proceedings of Conference 
on Operational Water Management, 137-148. 3-6 September 1997, Copenhagen. AA Balkema.

Sahoo, G. B., and C. Ray. 2006. Flow Forecasting for a Hawaii Stream using Rating Curves and Neural Networks. Journal of Hydrology 340 (1-2): 119-21.

SCS (Soil Conservation Service). 1972. National Engineering Handbook, Section 4. Washington, DC: U.S. Department of Agriculture.

Subramanya, K. 1991. Engineering Hydrology. New Delhi: Tata McGraw-Hill Publishing.

Thielen, J., J. Bartholmes, M.-H. Ramos, and A. de Roo. 2009. The European Flood Alert System-Part 1: Concept and Development. Hydrology and Earth System Sciences 13 (2): 125-40.
Tsai, C. W. 2005. Flood Routing in Mild-Sloped Rivers-Wave Characteristics and Downstream Backwater Effect. Journal of Hydrology 308 (1-4): 151-67.

U.S. Army Corps of Engineers. 2000. Hydrological Modelling System HEC-HMS Technical Reference Manual. Davis, CA: U.S. Army Corps of Engineers, Hydrologic Engineering Centre. -. 2001. Hydrological Modelling System HEC-HMS User's Manual. Davis, CA: U.S. Army Corps of Engineers, Hydrologic Engineering Centre.

-. 2003. Geospatial Hydrological Modelling Extension HECGeoHMS, User's Manual. Davis, CA: U.S. Army Corps of Engineers, Hydrologic Engineering Centre.

Open Access This article is distributed under the terms of the Creative Commons Attribution License which permits any use, distribution, and reproduction in any medium, provided the original author(s) and source are credited. 